INDO GLOBAL JOURNAL OF

PHARMACEUTICAL SCIENCES

ISSN 2249- 1023

\title{
Methods for Development of Biofilm Resistance
}

\author{
Sharanya Sinha, Reema Gabrani * \\ Department of Biotechnology, Jaypee Institute of Information Technology, A-10, Sector-62, Noida -201309, Uttar Pradesh, India
}

Address for Correspondance: Reema Gabrani, reema.gabrani@jiit.ac.in

\section{Keywords}

Antibiotics; Efflux

Pump; EPS Matrix;

Extracellular DNA.

\begin{abstract}
Biofilm is a cluster of bacteria attached to a surface and to each other by a self secreted matrix of extracellular polymeric substance (EPS). Bacteria enclosed inside the biofilm matrix have significantly higher resistance towards antibacterial and anti-biofilm agents, as compared to free floating planktonic bacteria. The fact that biofilms are the root cause of various bacterial infections like indwelling medical device-associated infections, urinary tract infections, middle-ear infections, and many nosocomial infections, is a major reason why their extremely resistant behaviour is a threat. Bacteria enclosed inside the biofilm attain their increased resistance by the combined effect of various factors towards antibiotics. The EPS matrix surrounding the bacterial cells acts as the primary barrier and provides a shielding effect against a penetrating antibiotic. It also secretes substances that help the matrix get more robust. A component of the EPS matrix, extracellular-DNA, also aids in providing increased antibiotic resistance ability via a complex regulatory system. Other mechanisms adopted by the biofilm bacteria are starvation induced stress response and Efflux Pumps. Understanding the architecture and nature of biofilm resistance, can help the researchers to design strategies and develop drugs that can combat the resilient infection. (C) 2016 iGlobal Research and Publishing Foundation. All rights reserved.
\end{abstract}

Conference Proceedings: International Conference on Advances in Plant and Microbial Biotechnology (PMB2017); JIIT, Noida: February 02-04, 2017

Indo Global Journal of Pharmaceutical Sciences( ISSN 22491023 ; CODEN- IGJPAI; NLM ID: 101610675) indexed and abstracted in EMBASE(Elsevier), SCIRUS(Elsevier),CABI, CAB Abstracts, Chemical Abstract Services(CAS), American Chemical Society(ACS), Index Copernicus, EBSCO, DOAJ, Google Scholar and many more. For further details, visit http://iglobaljournal.com 